\title{
Adult Daughters of Victimized Mothers: Navigating Relationships with Fathers Who Abuse
}

\author{
Kim Anderson ${ }^{1, *}$, Andrea L. Roach ${ }^{2}$ \\ ${ }^{1}$ School of Social Work, Public Affairs Program, University of Central Florida, USA \\ ${ }^{2}$ Department of Child, Family, and Consumer Sciences, California State University, USA
}

\begin{abstract}
This article reports on a qualitative study that examined how adult daughters $(N=17)$ of victimized mothers navigate relationships with fathers/stepfathers who abuse their intimate partners. Through the use of purposive sampling and the grounded theory method, participants' intentional decision-making involved upholding self-preservation while distinguishing relationship boundaries with their abusive father figures. Three adult daughter-father relational categories emerged depicting the tenuous balance between maintaining self and engaging in paternal contact: self-defend, self-sustain, and self-transcend. Each grouping included key emotional, cognitive and behavioral processes for adult daughters in regard to relationship commitment, support, and contact with their fathers/stepfathers. This study's findings contribute to a gap in knowledge regarding possible processes and consequences for adult daughters in negotiating relationships, including caregiving assistance, with partner-abusive fathers/stepfathers. Such knowledge informs the feminist, child development and fathering literature and opens up possibilities for further study in domestic violence research.
\end{abstract}

Keywords Intimate Partner Violence, Children Exposed to Domestic Violence, Fathering

\section{Introduction}

Domestic violence research indicates that witnessing inter-parental violence as a child has lasting consequences, yet a neglected area of inquiry is the relationship between fathers, who abuse their intimate partners, and their adult daughters (Anderson, 2012; Anderson, Danis, \& Havig, 2011; Band-Winterstein, 2014; Guille, 2004; Humphrey, 2001). As child witnesses age, they continue to be exposed to their parents' abusive or conflictual relationship, regardless if their parents separate or remain intact
(Anderson, Danis, \& Havig, 2011; Humphreys, 2001). In other words, once a child becomes an adult and leaves his/her family home, this does not mean that they are no longer exposed to parental IPV. Albeit such exposure might not include the frequency and intensity as witnessed during childhood, it still is impactful and may continue to influence their perceptions of self, intimacy, and parental relationships. "Most research on the adult effects of abuse have focused on sexual and physical abuse, and far less is known about how witnessing domestic violence as a child affects adult women in particular" (Becker, Stuewig, \& McClosky, 2010, p. 1701). Understanding the emotional, cognitive, and behavioral responses that adult daughters engage in when navigating their relationships with their partner-abusive fathers is important for comprehending the well-being of individuals in that situation (Dick, 2006; Moon, 2000). As a result, we may expand our contextual understanding regarding the possible trajectories of these relationships and may offer further insights regarding the long-term outcomes of child witnesses. This current study, therefore, set out to further explore the processes and consequences of continued relationships between partner-abusive fathers and their adult daughters. The term often associated with childhood exposure is domestic violence; however, for adults who experience abuse in intimate relationships the current lexicon is intimate partner violence (IPV). Consequently, both terms will be used interchangeably to identify heterosexual relationships where a male is perpetrating violence toward a female intimate partner.

\section{Long-term Relational Consequences for Child Witnesses}

The studies of adults, who witnessed domestic violence as children, often investigates whether or not they perpetuate the cycle of violence, rather than addressing their prolonged exposure to parental IPV. While child 
witnesses include boys and girls, a few studies report gender differences regarding the impact of witnessing IPV (Evans, Davies \& DiLillio, 2008; Fagan \& Wright, 2011; Herrera \& McCloskey, 2001). Thus, exploring separately each gender's developmental trajectory allows for gender-based relevant discovery and explication of short and long-term impacts. For example, compared to non-exposed men and women in intimate heterosexual relationships, males are more likely to show violent and aggressive behavior toward their female partners (Dick, 2006; Murrell, Merwin, Christoff, \& Henning, 2005), and females are more likely to be the recipient of men's violence (Maker, Kemmelmeier \& Peterson, 1998). For young girls, seeing their mothers physically and emotionally harmed by male partners may reinforce cultural messages about women and men's roles in society and within the family.

Adult children are also more likely than non-exposed counterparts to resolve conflict in relationships by avoidance or aggression, resulting in poorer social adjustment, fewer attachments, and intimacy difficulties related to mistrust and fears of abandonment (Henning, et al, 1997; Von Steen, 1997). Thus, adult daughters who witness parental violence may have a significant amount of hurt and trauma to deal with as they age, particularly if such exposure continues into adulthood. Furthermore, the social expectation that women will care for family members endures, regardless if many women have difficult or abusive past relationships with their parents (Wuest, Hodgins, Malcolm, Merritte-Gray, \& Seaman, 2007). In Anderson's (2012) inquiry into life trajectories of adult daughters' $(N=68)$, the majority $(87 \%)$ reported having significant family responsibility during childhood. It was not uncommon for such family expectations and roles to continue in adulthood, because daughters often continued to live and work in the same geographic communities as their parents and remain connected to them. The current study takes a further look at how adult daughters continue to look for ways to better understand and heal from their fathers' violence toward their mothers.

\section{Adult Child-Parent Relationships for Child Witnesses}

The parent-child relationship is considered to be among the most lasting and emotionally close relationships in which individuals engage. However, as in the case of intimate partner violence, the actions of the parent may stress such relationships (Brann, Rittenour, \& Myers, 2007). Consequently, children's perceptions of parental behaviors may continue to have an impact on their relationships as they age into adulthood. For instance, male adult children from partner-abusive households view their fathers as less responsible and accessible to them than individuals who did not experience childhood exposure to domestic violence (Dick, 2006). Moon (2000) found that adult children were less likely to report relational commitment and satisfaction of fathers who had physically and/or verbally abused their female partners. In addition, adult children often distanced themselves (physically and emotionally) as an avenue of protection from their parents (Anderson, Danis, \& Havig, 2011; Moon, 2000).

Band-Winterstein (2014) studied adult children $(N=25$, 12 males and 13 females) and their aging parents within the context of lifelong intimate partner violence. In doing so, the author provided an overview of how the long-term effects of such exposure impacted adult children's assistance, support, and commitment as caregivers to their elderly parents. Their findings indicated how some adult children offered assistance as they were assigned the caregiver role during childhood. As a result, they often viewed their continued obligation as a burden. Others rejected such a role in adulthood often because their parents did not reciprocate support. Yet, they felt a sense of guilt as they perceived themselves as irresponsible daughters/sons. Or, they assumed a caretaking role despite their own personal suffering, not as an obligation, but more of a choice based on one's personal expectation of what it means to be a family member. Consequently, such results highlight how violence exposure is an important indicator of how adult children process their role as parental caregiver, including a sense of obligation and responsibility.

In the particularly case of adult daughters of abused women, they often have conflicted feelings that may range from empathy to resentment toward both their abusive and victimized parents (Anderson, Danis, \& Havig, 2011). As a result, they try "to distance themselves from absorbing or reflecting their families' problems" and emotionally separate from the "drama" of one or both of their parents (Anderson \& Danis, 2006, p. 427; Anderson, Danis, \& Having, 2011). The current study takes a closer look specifically at how adult daughters navigate relationships with their fathers, including maintaining, minimizing, or stopping contact with them. To understand such choices and its impact, this study's results may provide valuable information on adult daughters who are trying to navigate role obligation, responsibility, and conflict under the influence of intimate partner violence. In doing so, we may learn more about adult daughters' agency in navigating complex and difficult family relationships, realizing the ability to do so will be influenced in part by their childhood history. Our current study, therefore, may contribute to a more complete understanding of the process of adult adaptation that takes into account ongoing relationships with fathers/stepfathers who abuse their female partners.

\section{Method}

The present study set out to further explore adult 
daughters' relationships with partner-abusive fathers/stepfathers. Because the intent of this study was to discover how one navigates such relationships, the grounded theory method was particularly suited as its purpose is to identify complex and hidden psychosocial processes (Glaser, 2001). This approach involves being "immersed" in the world viewpoints of the participants and allows for the influences of context on experience and meaning to be illuminated. The research questions included:

1. How do adult daughters navigate relationships with fathers/stepfathers who abuse?

2. What are the processes and consequences of navigation, including their impact on paternal contact?

\section{Sampling Method}

This convenience sample was drawn from a large mixed methods study regarding recovery and growth in adult daughters $(N=68)$ exposed to IPV during their childhood (Anderson \& Bang, 2012). Purposive sampling criteria for the larger study included adult children who met the following criteria: 1) 21 or older, 2) not living in their parents' home/childhood residence, and 3) had experienced (during childhood) their mothers being abused by intimate male partners in the household in which they were reared. Additional inclusion criteria for the current study included those participants whose parents remained together and the abuse of their mothers by their fathers/stepfathers continued in adulthood. Seventeen participants met such criteria.

\section{Participant Characteristics}

Participants $(N=17)$ ranged in age from 20 to 54 years old $(M=33, S D=9.77)$. The majority were European American $(n=14)$, one was Asian, one was African, and one was African-American. This was a highly educated sample, 10 (56\%) participants had completed a bachelor's and/or master's degrees, three completed vocational school or community college, and four were high school graduates Seven $(41 \%)$ participants reported experiencing violence in past intimate partner relationships of their own.

Abusers included their fathers $(n=14)$ or stepfathers $(n=3)$. In all cases adult daughters were exposed to paternal partner-violence in adulthood; eight reported the abuse was currently occurring. Five reported nine or less years of exposure in adulthood, ten reported 10-20 years $(M=15)$, and two reported 21 or more years. The types of IPV reported by all participants included exposure to physical (e.g., hitting, punching, choking, and/or shoving of their mothers) and emotional abuse (e.g., swearing, yelling, threatening, name calling, and/or screaming at their mothers). Eight adult daughters (47\%) reported that the abuser had an alcohol problem. Additionally, 11 participants reported that during childhood their fathers/stepfathers also abused them.

\section{Procedure}

After approval by a university internal review board, participants were recruited through electronic advertisements to students, faculty, and staff at a Midwestern University in the United States. Potential participants were screened over the telephone by the first author to explain the interview process and to determine whether they met sampling criteria. Although intimate partner violence also includes abuse by women against men and same-sex partners, the focus was on the experience that most children are exposed to where a man is using coercive control to perpetrate violence against an adult woman (Edleson et al., 2007; Stark, 2007). Patterns of violence included physical, verbal, sexual, and financial. Childhood exposure was defined as being within sight or sound of the violence or witnessing the aftermath of the violence (e.g., mother's injuries, property destruction, police intervention to remove the abuser, moving to a domestic violence shelter) (Edleson et al., 2007). Interviews were conducted in the first author's University office.

Although a semi-structured interview of open-ended questions was used, participants determined the emphasis they would place on different aspects of their stories and they were given the freedom to describe the meaning they had given to their own experiences. Each interview began by the researcher asking participants to pick a pseudonym and to share their lifelong experiences of exposure to intimate partner violence. For the purposes of the current study, we examined content from the initial study regarding how participants' thoughts, feelings, and behaviors changed over time in regard to their relationships with their parents, particularly their fathers/stepfathers, and what contributed to such change. Member (participant) checking included a 30-minute follow-up interview with participants to gain their insights regarding the findings. At the conclusion of the second interview, participants were given a \$20.00 gift certificate to a national department store.

\section{Data Analysis}

Data (e.g., interview transcripts) were coded and organized by two researchers using a constant comparative method; a qualitative procedure that identifies and extracts significant statements or "meaningful units" from in-depth interview transcripts to be conceptualized and reconstructed in new ways (Oktay, 2012). Initially, analysis involved searching for units of data (i.e., attitudes, beliefs, values, feelings, impacts) that were associated with the overall purpose for the study regarding how adult daughters' navigate relationships with their fathers. Using 
in-vivo or open coding, each line of the transcript was assigned an action code directly related to each interview question (e.g., setting boundaries, questioning fathers' actions, etc.). During this initial stage of coding, researchers utilized the words and ideas of the respondents to better understand their experiences and to designate data into early categories of "conveyed meanings" (Oktay, 2012, pg. 55). Next, axial coding was utilized in order to understand how these conveyed meanings were related to one another, to identify central themes of the adult daughter navigation process (Oktay, 2012). Finally, selective coding was used to group data into final categories that represented key psychosocial issues and patterns (i.e., emotional, cognitive, and behavioral responses) related to navigation. These patterns were analyzed by comparing them with one another, so that relevant themes (i.e., self-defend, self-sustain, and self-transcend) addressing the research questions could emerge.

\section{Results}

\section{Navigating Adult Relationships with Fathers}

This study's results depict the delicate balance for adult daughters as they struggled to protect and maintain a sense of self while navigating relationships with their abusive father figures. For these participants, relational decision making was not necessarily influenced by the actions of their fathers/stepfathers, as they did not identify instances of reciprocal support, understanding, or intimacy. Instead, navigating the adult daughter-father relationship involved a range of emotional, cognitive, and behavioral responses across three categories of self-preservation: self-defend, self-sustain, and self-transcend. All categories included participants with variation in exposure including current partner violence.

1. Self-defend: Participants ( $n=6,4$ fathers, 2 stepfathers) focused on protecting and defending a sense of self while opposing their fathers/stepfathers' abusive actions and relationships with them. Emotionally, they experienced intense anger, hatred, and sadness. Cognitively, they attributed the cause of abuse to their fathers/stepfathers being bullies who were controlling, mean, and brutal. Behaviorally, they discontinued contact with their fathers/stepfathers, as they saw no benefits to maintaining relationships. Participants chose not to be a part of their parents' violent lives, as they viewed it as fruitless not to mention life threatening. Therefore, they did not assume a caretaking role with them.

2. Self-sustain: Participants ( $n=5,4$ fathers, 1 stepfather) focused on sustaining a sense of self in the midst of withstanding relationships with their fathers/stepfathers while not condoning the abuse. Emotionally, they experienced mostly negative emotions, particularly anger and irritation. Cognitively, they attributed the cause of abuse to their fathers/stepfathers being flawed individuals (e.g., mental health problems, intergenerational transmission of violence). Behaviorally, they were ambivalent about maintaining relationships with their father figures, but did so as they saw benefits for their mothers. Participants had a sense of obligation regarding protecting and supporting their mothers as a means of providing justice to them. They expressed emotional ambivalence regarding caretaking responsibilities toward their parents.

3. Self-transform: Participants ( $n=6$, all fathers) focused on a sense of self (e.g., altruistic) that transcended their suffering while actively seeking relationships with their fathers. Emotionally, they experienced both negative and positive emotions, including compassion and empathy toward their fathers. Cognitively, they viewed the cause of the abuse as their fathers being anguished human beings. Behaviorally, they initiated relationships with their fathers as they saw benefits for themselves, their parents, and the family unit. They depersonalized their caretaking role as they saw it as a daughter's commitment rather than obligation.

\section{Self-defend}

Participants ( $n=6, M$ age=36, age range 22-54) focused on protecting and defending a sense of self while opposing their fathers/stepfathers' abusive actions and relationships with them. Participants in this category were exposed to more physical violence by their fathers toward their mothers than any other grouping. In comparison to the other groupings, this category experienced the second highest percentage of exposure to current intimate partner violence, the lowest percentage of those who had experienced child abuse, and the highest percentage (along with the self-transform category) of paternal substance abuse. Characteristics of this group included three whose fathers $(50 \%)$ were still abusive toward their mothers. Three $(50 \%)$ experienced child abuse and five $(83 \%)$ experienced paternal substance abuse.

The adult daughters within this category expressed relief that they no longer had contact with their fathers/stepfathers. Any positive feelings between family members, particularly child-parent, had been destroyed by the violence and replaced with fear, terror, and uncertainty. These women discussed various emotional, cognitive, and behavioral coping strategies that led them to make a decision of ceasing contact.

Had I known the feeling that I would have, the feeling that I felt the day I walked away from my dad, if I would have known I could have done that, I would have done it when I was 20. (Phyllis, age 54) 
Emotionally. Participants experienced intense anger, hatred, and sadness toward their father/stepfather, some negative affect toward their mother (e.g., resentment for remaining in the relationship too long), and a damaged relationship with both. Adult daughters reported how their father figures continued to engage in behaviors that were threatening, physically and/or verbally, to their mothers, themselves, or their other family members.

And so that really disturbed me quite a bit that... [my father is] 55 years old, I'm an adult and married, and you're still trying to pick up two by fours and bully me, not only me now, but also my husband, into getting what you want. And so that for me was kind of the last straw. I was done with it at that point and have been ever since. (Rebekah, age 27)

Cognitively. Participants attributed the cause of abuse to their fathers/stepfathers as predominantly being controlling, mean, and brutal. Five of the participants acknowledged that alcohol was a problem for their fathers/stepfathers, and that it changed his behavior, but they did not see it as the cause of his abusive behavior, but merely added to it. Additionally, knowledge of their fathers/stepfathers' own childhood experiences with violence provided a context for his actions, but it did not engender empathy towards them.

I don't think it would have made any difference had I known how violent his family truly was, but at least as an adult you think, 'Well, he was in it, too.' I mean he actually did not have an easy life. He truly did not. But, you know what, that is not an excuse. (Lynne, age 22)

Participants were resistant to reporting any similarities (positive or negative) with their fathers/stepfathers; instead, they were much more likely to focus on positive comparisons with their mothers.

I'm his daughter and I'm sure that he's in there, but for me to sit and admit that I'm anything like him, no, that's not gonna happen. He was lazy, he was brutal. I have nothing good to say. I realized that my mom I'm like her in ways. I'm strong. She was a strong woman even though she put up with that, she was still a strong woman. She managed to keep going and keep the house together and keep us fed and clothed. I think she just went and went and went. (Phyllis, age 54)

Behaviorally. Participants discontinued contact with their fathers/stepfathers, as they saw no benefits to maintaining these relationships. These women made the decision to end contact with their father figures in any form, often also at the cost of no longer speaking to their mothers. Although participants were firm in their decision to stop contact, they were ambivalent about whether or not to work on the relationship in the future.

Do I never talk to my parents again, let it be the way it is, and go on with my life, or do I try to have a relationship with them? Is that the right thing to do? And so I guess that's probably my biggest struggle right now is just trying to figure that out. Do I try to work it out with him, cause I know he won't be here much longer, or do I just accept the fact that even if I tried working it out with him he wouldn't understand? (Rebekah, age 27)

\section{Self-Sustain}

Participants ( $n=5, M$ age $=31$, age range 20-47) focused on sustaining a sense of self in the midst of withstanding relationships with their fathers/stepfathers while not condoning the abuse. This category had the highest percentage of participant exposure to current violence and the highest percentage of participants experiencing child abuse. In addition, participants in this grouping were the most ambivalent regarding continuing relationships with their fathers. Characteristics of this group included three $(60 \%)$ women whose fathers were still abusive toward their mothers. Four $(80 \%)$ experienced child abuse and no one reported experiencing paternal substance abuse.

These adult daughters discussed the importance of maintaining family relationships, but were unable to have a close relationship with their fathers/stepfathers. However, they believed the benefits of connecting with their fathers, and thus helping their mothers, outweighed the costs to themselves.

Well, in my counseling sessions they tell me there is closure. They tell me the way to get closure is to confront the problem, or leave the problem. I'm not willing to confront him. He sees no wrong in himself, so really I'd just be beating my head against the wall. And leaving the problem would mean I would never get to see my mother again. So I try to ignore it unless it flares its ugly head while I'm there, and that's the only way I can cope with it. (Terry, age 47)

Emotionally. They experienced mostly negative emotions, particularly anger and fear. Such feelings occurred, in part, due to their fathers/stepfathers not changing their abusive behaviors.

I still can't stand my dad for what he did. However, I go around my father to see my mother. I still think it was wrong, and I still think it's wrong to this day what he does, but I'm very scared of my dad. And he still acts like a butt, and it scares me to death and I have to just leave because I get so upset that I physically get ill. I know one of these days my father's going to pass away, and I'm probably not gonna be as sad as I should be. (Terry, age 47)

Additionally, participants' expressed irritation toward their fathers/stepfathers for not taking responsibility of their actions and instead blaming their partners, the victims, for the abuse. 
He's (stepfather) tried to get into these conversations with me where he tries to point out the things that my mother did wrong, and my heart starts to beat really fast and I just want to get off the phone. I don't want to talk to him. I turn the conversation and I won't hear anything that he has to say. He tries to vindicate himself or whatever, and I will have nothing of it. (Heather, age 37)

Cognitively. Participants sought understanding of causes of their fathers' action, as a means of understanding, but not condoning, why he acted the way he did.

I asked my grandmother. His father was an alcoholic and beat him badly. So my grandmother left, I think she said when he was 14 or 15 . So, of course, he remembers being beaten. She thinks that's why he was mean to us. (Terry, age 47)

The women in this category were able to express similarities with their fathers/stepfathers but they were negative in nature, characteristics that they did not necessarily want to have in common. They acknowledged these similarities existed but were adamant that they were not as severe as their father figures' actions. Furthermore, they shaped their identities more by perceived paternal differences rather than commonalities.

As far as my dad, I have his temper, but I also know how to keep it in check. I was influenced by these two people who raised me, and for me to come out the way I did they have to have done a halfway decent job. So I do have a bit of both of them in me, but I also know what parts I don't want. I will never, ever be, like my father was. (Amy, age 27)

The women in the self-sustain category often reported they had a special relationship with their mothers that they were not willing to sacrifice; therefore, they maintained contact (not necessarily a relationship) with their father figures as a means of offering assistance, support and protection to their mothers.

My feelings about my mother have not changed. I feel very sorry for my mom. My mom's the nicest person in the world. She never says anything bad about anybody. I can go places with [my father] as long as my mom's there, but I don't have a very good relationship with my dad. I do with my mom. I did ask one day why my mother was staying with my father, and she told me. She said that he told her if she ever left he would kill her kids, and told her exactly how he would do it. So she said, 'I don't ever want anything to happen to my children, so I stay.' And now she's just kind of dead inside. (Terry, age, 47)

Behaviorally. Participants were ambivalent about maintaining relationships with their father figures, but did so as they saw advantages for their mothers and for the family in general. In other words, these adult daughters accepted a relationship with their fathers/stepfather as it benefitted others, yet they controlled the type of contact as a means of protecting themselves.

He'll call [stepfather)] and we'll talk on the telephone and I've seen him several times for holidays because he just thinks he's a completely normal guy, so he'll call me and he doesn't feel anything weird about doing that at all. And I have had a good life, so I'm fine with him calling me. I can talk to him for a while on the telephone, so it's not a big deal. (Heather, age 37)

\section{Self-transform}

Participants ( $n=6, M$ age $=33$, age range 24-50) focused on a sense of self (e.g., wanting to help) that transcended their suffering while actively seeking relationships with their fathers. This category had the lowest percentage of current violence exposure, the second highest percentage of child abuse, and the highest percentage (tied with self-defend category) of paternal substance abuse. Characteristics of this group included two whose fathers (33\%) were still abusive toward their mothers. Four $(67 \%)$ experienced child abuse and five (83\%) experienced paternal substance abuse.

Participants actively sought out contact because it benefited themselves (e.g., right thing to do), parents and family. These women put aside their own discomfort when they interacted with their fathers as they viewed it as best for him and the family. They sorted through past experiences including what was passed on to them by each parent, finding and keeping what was useful while discarding the rest. Participants spoke of coming to understand their parents' shortcomings, as well as their own. Acceptance of both human capacity and of limitations (for themselves and their fathers) allowed for an acceptance of the situation.

I'm okay with having enough of a relationship with him that I don't have regrets and that maybe he can look back on his life or look to the future of his relationship with me and feel like there's been some healing. But I don't ever expect to have a great, close father/daughter relationship with him. I'm okay with just talking to him or seeing him every once in a while and being there, but not expecting anything close. (Rhonda, age 34)

Emotionally. Participants experienced both negative and positive emotions, including compassion and empathy toward their fathers. They sought understanding for their fathers' actions while trying to be a positive factor in their lives.

I knew it wasn't normal, but I still kind of understood it. I grew up with empathy, like I came out the womb with empathy. And so I always empathized with him so I would never see him as an abuser, I just kind of 
saw him as he just had problems. He was neglected as a child and abandoned by his parents. He had alcohol problems. My mother said he was never right after he came back from the war because he had gone to Viet Nam. So he had a lot going on with him. I was the closest to him. (Kay, age 34)

For half of the participants, the ability to accept their fathers partly came from them changing their abusive behaviors, although they continued to exhibit negative relationship qualities including emotional unavailability and inadequate communication.

He's changed a lot because of his relationship with Christ, so have I. I just really started encouraging a little bit of a relationship with him a couple of years ago. One day I just felt like I should call him and talk to him. I hadn't spoken with him in several years. We had a good phone conversation, and I've now gone to see him twice, and it's kind of like he's the kid and I'm the adult. He doesn't know how to communicate with my husband and I. (Rhonda, age 34)

Cognitively. Participants attributed the cause of the abuse as their fathers being anguished human beings and this allowed them to have the empathy and compassion necessary to maintain a relationship. They accepted their fathers' faults as well as their strengths. Additionally, they were able to identify paternal similarities (both positive and negative) along with differences.

Well, my internal makeup, like I have his teeth, I have his face shape. He has an engineer type mind, so he likes to build and make things. I'm like that. I think I'm more like, even though I didn't like this for a long time, I'm a lot more like my dad like as far as personality. He's very outgoing, very bubbly, people person, assertive. I mean my father did have some good qualities, even though he was an abusive person. (Rhonda, age 34)

Behaviorally. Participants initiated relationships with their fathers as they saw benefits for themselves, their parents, and the family unit. Additionally, they offered parental assistance, support and protection. Ultimately, they wanted to positively impact their parents' well-being.

I think I was doing it for my mom. I was helping my dad for my mom, really. I don't know if I would have if it was just my dad, and if it wasn't my mom. I don't know if I would have been so attentive, but my mom was struggling, and she still loved my dad, and was faithful to him even though he was mean to her. (Lisa, age 50)

\section{Discussion}

The current study took a further look at how adult daughters navigate relationships with their partner-abusive fathers and the consequences of doing so. Such context is relatively unknown as the enduring daughter-father relationship has received minimal attention in the professional literature on IPV (Anderson, 2012; Anderson, Danis, \& Havig, 2011; Humphrey, 2001). The key psychosocial pattern discovered included adult daughters' struggle to protect and maintain a sense of self while navigating adult daughter-father relationships. Decision-making involved weighing the personal benefits and costs of the relationship (or lack thereof), along with the impact on self, parents, and other family members. These adult daughters were more likely to have set aside or overcome their violence exposure rather than their fathers/stepfathers changing and/or taking accountability for their actions. Even if the intensity and frequency of violence had lessened over time, their father figures' negative behavioral patterns (e.g., aloofness, detachment) remained. Adult daughters presented an array of emotional, cognitive and behavioral processes depending upon the self-preservation category: self-defend, self-sustain, and self-transcend.

The intensity of emotions toward their fathers/stepfathers differed between groupings, with the most extreme (negative) occurring in the self-defend group. Throughout their life span, this category had the highest exposure toward paternal substance abuse and physical violence of their mother. Such experiences provoked intense fear and anger. In comparison, emotions were more moderated for those in the self-transcend category and included both positive (e.g., empathy) and negative feelings towards their father figures. The percentage of those experiencing on-going violence exposures was least in the self-transcend category. As a result, perhaps these adult daughters were more able to step back and view their fathers' actions from a safer distance, and thus empathic, vantage point. Linley and Joseph (2004) noted that having distance can begin the process of deconstructing old schemas and world views of the nature of families, relationships, accountability, and other previously unchallenged ideas about life that were part and parcel of the abuse environment.

Cognitive processes for all participants involved attributing the cause of the violence to their fathers/stepfathers, yet levels of understanding and acceptance regarding factors impacting those actions varied. For some, they viewed the violence as endemic to their father's character (self-defend), while others (self-sustain, self-transcend) viewed it as a character shortcoming which provided an understanding, but not an excuse for his abusive actions. Adult daughters in the self-defend category not only questioned why their fathers were abusive, but also why their mothers endured it. They struggled with understanding this dynamic more so than those in the other categories perhaps because the violence they witnessed was more severe. They had more difficulty 
separating the abuser from the act of violence which can occur as the level of the father's aggression increases toward the mother (Winstok, Eisikovits, \& Karnieli-Miller, 2004).

Behavioral processes for all participants included distancing themselves (emotionally and/or physically) from their fathers/stepfathers. Adult daughters in the self-sustain group were the most ambivalent about maintaining current parental connection, while those in the self-defend category were unsure of whether or not to work out contact in the future. The self-sustain participants also experienced the highest percentage of violence exposure and child abuse. They identified with their mothers as victims and the complexity of navigating the external constraints of their fathers/stepfathers' abuse. They felt a strong obligation to protect their mothers while wanting to distance themselves from their fathers for self-protection. Von Steen (1997) also identified in her clinical practice that adult children with witnessing histories were unsure of how to relate to their family members and often talked about feeling conflicted. This struggle between protecting their mothers versus themselves was the most poignant in this grouping. Although, the current study focused on overall perceptions of witnessing domestic violence and not one's own childhood abuse, we learn that both may shape perspectives regarding parental relationships.

Exposure to domestic violence not only impacts child witnesses' perceptions of their parents, but of themselves also (Winstok, Eisikovits, \& Karnieli-Miller, 2004). These adult daughters did not believe that closure was possible, yet they recognized how their experiences had shaped them into who they were today. This knowledge lends itself to practice in that women should not be advised to seek closure, but rather acceptance of themselves. For some (self-defend) they viewed their adversity as something that happened to them, but it was not about them. For others (self-sustain) they viewed it as contributing to defining who they were (including paternal similarities and differences), while those in the self-transcend category viewed their hardships as transforming them to be better people (more compassionate, understanding) than what might have otherwise been. Such changes in the aftermath of stressful or traumatic life experiences, as in the self-transcend category, are often referred to as "posttraumatic growth" and highlight the human capacity for transformation in even the most ominous circumstances (Tedeschi, Park, \& Calhoun, 1998).

\section{Limitations of the Study}

While this study provided valuable information regarding the adult child-paternal relationship that exists between daughters and partner-abusive fathers, there are additional topics that need to be analyzed in more depth. For instance, some participants had several adverse childhood experiences and, as such, all of these experiences had an impact on their life course trajectory. Consequently, further exploration of processes and consequences of continuing relationships between abusive fathers and their adult daughters that takes into account additional familial risk and protective factors is necessary to expand our contextual understanding of adult relational categories. Additionally, the sample size was limited where 14 of the 17 participants were Caucasian, limiting the generalizability of the results for the larger population.

\section{Implications}

This study's exploration of relationship processes and consequences between fathers who abuse and their adult daughters provides scholars, educators, and helping professionals a contextual understanding of the possible trajectories of such connections over the lifespan. Relational groupings identified in this study may be conceptualized as fluid rather than progressive; therefore, it is possible that adult daughters may be in one or more categories throughout their lives depending upon how they assess the benefit/cost ratio for themselves in navigating paternal relationships. Adult daughters may seek domestic violence services and/or counseling in the process of trying to better understand the situation and alter cognitive, emotional, and behavioral responses in procuring adult agency, including the amount of contact they choose to have with their parents, particularly their fathers. Implications for practice include knowledge that some daughters will not have contact with their fathers, whereas others may be open to continuing it. Distancing themselves from their fathers and creating safety plans for themselves and their mothers may be most essential to those exposed to long-term and ongoing physical violence by their fathers toward their mothers. For those whom violence exposure has ended it may provide them with a path to examine and confront the reality of the past from a safe, detached standpoint. Equipping them with domestic violence educational information may provide an opportunity to see their parents from a lens of empathy and give them a sense of control and understanding of their situation.

In addition, the findings of this inquiry inform feminist empowerment theory, child development and fathering literature and opens up possibilities for further study in domestic violence research. Further research is necessary into the perceptions of men who abuse regarding their parenting roles and how their violent actions affect their children, particularly across the lifespan (Guille, 2004). "Our understanding of the relationships between children and victimized and abusive parents has focused mainly on these experiences during childhood" (Jaffe, Wolfe, \& Campbell, 2012, p. 10). The results of this study add to the literature of adult-child relationships within the context of exposure to domestic violence and highlights how the effects of paternal behaviors do not necessarily decrease as 
daughters grow older and, often, continue to affect the quality of the current relationship. Additional research may offer direction for preventive and proactive interventions across the lifespan that allow for the possibility that relationships between adult daughters and their partner-abusive fathers may change over time.

While this study has provided important information regarding the adult child-parent relationship that may exist between daughters and partner-abusive fathers, there are many topics that need to be analyzed in more depth. Since this study was an analysis of secondary data, it would be beneficial to conduct a study that specifically addresses how adult children navigate their relationships with their parents after or during domestic violence. Examining the continued relationship between adult-child and parents within the context of family violence is important because immediate family relationships are usually considered to be lifelong commitments or obligations. As a result, there is a need to understand how these relationships progress and what the impact of prolonged exposure to family violence is on the adult-child. Longitudinal research would be effective to analyze the decisions made over the course of a life-span and to more accurately assess the long-term impact of childhood and adolescent experiences.

\section{Conclusions}

This study's exploration of relationship processes and consequences between father figures who abuse and their adult daughters provides helping professionals a contextual understanding of the possible categories of such connections over the lifespan. As a result, our findings provide new knowledge for the domestic violence field regarding navigational pathways for adult daughters and their partner-abusive fathers. Common among the participants was the idea of consciously defining paternal boundaries, living by the rules they created for themselves, as adults in charge of their own lives, based on the lessons learned by enduring domestic violence exposure well into adulthood.

\section{REFERENCES}

Anderson, K. M. (2012). Fostering resilience in daughters of battered women. In D. Becvar (Ed). Handbook of Family Resilience (pp.495-514). New York: Springer Publishing.

Anderson, K. M., \& *Bang, E. (2012) Assessing PTSD and resilience for females who during childhood were exposed to domestic violence. Child \& Family Social Work, 17, 55-65.

Anderson, K. M., \& Danis, F. (2006). Adult daughters of battered women: Resistance and resilience in the face of danger. Affilia, 21(4), 419-432.
Anderson, K. M., Danis, F. S., \& Havig, K. (2011). Adult daughters of battered women. Recovery and posttraumatic growth following childhood adversity. Families in Society, 92(2), 154-160.

Becker, K.D., Stuewig, J., \& McClosky, L.A. (2010) Traumatic stress symptoms of women exposed to different forms of childhood victimization and intimate partner violence. Journal of Interpersonal Violence, 25(9), 1699-1715.

Band-Winterstein, T. (2014). The impact of lifelong exposure to IPV on adult children and their aging parents. Journal of Family Issues, 35(4), 439-461.

Brann, M., Rittenour, C.E., \& Myers, S.A. (2007). Adult children's forgiveness of parents' betrayals. Communication Research Reports, 24(4), 353-36.

Dick, G. (2006). Witnessing marital violence as children: Men's perceptions of their fathers. Journal of Social Service Research, $32(2), 1-24$.

Edleson, J. L., Ellerton, A. L., Seagren, E. A., Kirchberg, S. L., Schmidt, S. O., \& Ambrose, A. T. (2007). Assessing child exposure to adult domestic violence. Children and Youth Services Review, 29, 961-971.

Evans, S., Davies, C., \& DiLillio, D. (2008). Exposure to domestic violence: A meta-analysis of child and adolescent outcomes. Aggression \& Violent Behavior, 13(2), 131-140.

Fagan, A. A., \& Wright, E. M. (2011). Gender differences in the effects of exposure to intimate partner violence on adolescent violence and drug use. Child Abuse \& Neglect, 35(7), 543-550.

Glaser, B. G. (2001). The grounded theory perspective: Conceptualization contrasted with description. Mill Valley, CA: Sociology Press.

Guille, L. (2004). Men who batter and their children: an integrated review. Aggression and Violent Behavior, 9(2), 129-163.

Herrera, V. M., \& McCloskey, L. A. (2001). Gender differences in the risk for delinquency among youth exposed to family violence. Child Abuse \& Neglect, 25, 1037-1051.

Henning, K., Leitenberg, H., Coffey, P., Turner, T., Benett, R.T. (1996). Long-term psychological and social impact of witnessing physical conflict between parents. Journal of Interpersonal Violence, 11(1), 35-51.

Humphreys, J.C. (2001). Turnings and adaptations in resilient daughters of battered women. Journal of Nursing Scholarship, $33(3), 245-251$.

Jaffe, P., Wolfe, D.A., \& Campbell, M. (2010). Growing up with domestic violence. Cambridge, MA: Hogrefe Publishing.

Linley, P. A., \& Joseph, S. (2004). Positive change following trauma and adversity: A review. Journal of Traumatic Stress, $17(1), 11-21$.

Maker, A. H., Kemmelmeier, M., \& Peterson, P. (1998). Long-term psychological consequences in women of witnessing parental physical conflict and experiencing abuse in childhood. Journal of Interpersonal Violence, 13(5), 574-589.

Moon, M. (2000). Retrospective reports of interparental abuse by adult children from intact families. Journal of Interpersonal 
Violence, 15(12), 1323-1331.

Murrell, A. R., Merwin, R. M., Christoff, K. A., \& Henning, K. R. (2005). When parents model violence: The relationship between witnessing weapon use as a child and later use as an adult. Behavior and Social Issues, 14, 128-133.

Oktay, J.S. (2004). Grounded theory. In D. Padgett (Ed.), The qualitative research experience (pp. 23-46). Belmont, CA: Wadsworth/Thomson Learning.

Stark, E. (2007). Coercive control: How men entrap women in personal life. Oxford, England: Oxford University Press.

Tedeschi, R. G., Park, C. L., \& Calhoun, L. G. (1998). Posttraumatic growth: Positive changes in the aftermath of crisis.
Mahwah, NJ: Erlbaum.

Von Steen, P. G. (1997). Adults with witnessing histories: The overlooked victims of domestic violence. Psychotherapy, 34(4), 478-484.

Winstock, Z., Eisikovits, Z., \& Karneili-Miller, O. (2004). The impact of father-to-mother aggression on the structure and content of adolescents' perceptions of themselves and their parents. Violence Against Women, 10(9), 1036-1055.

Wuest, J., Hodgins, M.J., Malcolm, J., Merrite-Gray, M., \& Seaman, P. (2007). The effects of past relationship and obligation on health and mental health promotion in women caregivers of adult family members. Advances in Nursing Science, 30(3), 206-220 